\title{
Relation between iron stores and non-insulin dependent diabetes in men: case-control study
}

\author{
Jukka T Salonen, Tomi-Pekka Tuomainen, Kristiina Nyyssönen, Hanna-Maaria Lakka, \\ Kari Punnonen
}

Non-insulin dependent diabetes mellitus is a common complication of diseases of iron overload such as haemochromatosis; $53-80 \%$ of patients with haemochromatosis develop diabetes. ${ }^{1}$ The development of diabetes in haemochromatosis is related to the magnitude of the excess iron. ${ }^{1}$ In a cross sectional, population based study of over 1000 middle aged men in eastern Finland we found that fasting concentrations of serum insulin and blood glucose were raised in men with high serum concentrations of ferritin (an indication of raised stores of iron). ${ }^{2}$ Iron is a catalyst of free radical stress, and it has been suggested that free radicals and lipid peroxidation play a part in the aetiology of diabetes. ${ }^{3}$ Formation of hydroxyl radicals catalysed by iron may play an important part in the development of diabetes since the cells that produce insulin are extraordinarily sensitive to damage from oxidation. ${ }^{3}$ In another cohort study low plasma concentrations of vitamin $\mathrm{E}$ were associated with an increased incidence of diabetes, which supports this theory. ${ }^{4}$ There are, however, no other studies of the association between iron stores and the incidence of diabetes in a healthy population.

\section{Subjects, methods, and results}

We tested the hypothesis that the accumulation of iron in the body predicts the development of non-insulin dependent diabetes. We followed 1038 randomly selected men from eastern Finland aged 42-60 for four years; there is a high incidence of non-insulin dependent diabetes in eastern Finland. Fifty three men who were found to have diabetes at baseline (fasting blood glucose concentration $\geqslant 6.0 \mathrm{mmol} / \mathrm{l}$ or who were already receiving treatment for diabetes) were excluded. This low cut off point for fasting blood glucose was used to increase the sensitivity of the exclusion of participants so that all potential participants who had diabetes or who could have been classed as prediabetic were excluded.

We estimated iron stores by determining the ratio of the concentrations of transferrin receptors ${ }^{5}$ to ferritin in frozen serum samples drawn during baseline examinations. Serum samples from 41 men who developed diabetes during follow up and from 82 controls were analysed. The controls were matched by age, year and month of examination, place of residence (urban or rural), number of cigarettes smoked daily, amount of exercise taken each week (kcal expended per week), maximal oxygen uptake (a measure of cardiorespiratory fitness), socioeconomic status, height, weight, hip and waist circumferences, blood glucose concentration, serum insulin concentration, plasma lipid standardised vitamin $\mathrm{E}$ concentration, and the ratio of saturated fatty acids to the sum of polyunsaturated and monounsaturated fatty acids in serum at baseline. ${ }^{4} \mathrm{~A}$ participant was defined as diabetic at the end of follow up if he had a fasting blood glucose concentration $\geqslant 6.7 \mathrm{mmol} / \mathrm{l}$ (a higher cut off value was used to increase specificity), or a blood glucose concentration two hours after glucose loading $\geqslant 10.0 \mathrm{mmol} / \mathrm{l}$, or a clinical diagnosis of diabetes and was receiving dietary, oral, or insulin treatment. ${ }^{4}$

In a logistic regression model, men with high stores of iron (those in the lowest quarter of the ratio of transferrin receptors to ferritin, that is $<9.4 \mu \mathrm{g} / \mu \mathrm{g}$ ) were 2.4 times more likely $(95 \%$ confidence interval of odds ratio 1.03 to $5.5, \mathrm{P}=0.04$ ) to develop diabetes than men with lower stores of iron. In a step up model in which baseline concentrations of serum triglycerides and glycosylated proteins were adjusted for as continuous variables, the odds ratio for developing diabetes was 2.5 ( 1.1 to $6.0, \mathrm{P}=0.04$ ).

\section{Comment}

This is the first study to show an association between stores of iron and the incidence of diabetes. Our data support the theory that increased iron stores, even in the range not considered to be associated with haemochromatosis, contribute to the development of non-insulin dependent diabetes. Additional cohort studies and trials of iron depletion in people with increased stores of iron are warranted.

We thank Professor George A Kaplan, for his contribution in obtaining funding for the study, and the staff of the Research Institute of Public Health, University of Kuopio, who helped with the collection of data.

Contributors: JTS initiated the study, organised the collection of data, analysed the data, drafted the paper, and is guarantor for the paper. T-PT and H-ML searched the literature, helped in writing the paper, and discussed the core ideas. KP supervised the analysis of the transferrin receptor and ferritin ratios. KN supervised the analysis of most of the other chemical assays.

Funding: Academy of Finland (grant numbers 41471, 1041086, and 2041022 to Professor Salonen) and the National Heart, Lung, and Blood Institute of the United States (grant HL44199 to Professor George A Kaplan).

Conflict of interest: None.

1 Witte DL, Crosby WH, Edwards CQ, Fairbanks VF, Mitros FA. Practice Guideline Development Task Force of the College of American Pathologists: hereditary hemochromatosis. Clin Chim Acta 1996;245:139-200.

2 Tuomainen T-P, Nyyssönen K, Salonen R, Tervahauta A, Korpela H, Lakka $\mathrm{T}$, et al. Body iron stores are associated with serum insulin and blood glucose concentrations: population study in 1,013 eastern Finnish men. Diabetes Care 1997;20:426-8.

3 Oberley L. Free radicals and diabetes. Free Radic Biol Med 1988;5:113-24.

4 Salonen JT, Nyyssönen K, Tuomainen T-P, Mäenpää PH, Korpela H, Kaplan GA, et al. Increased risk of non-insulin dependent diabetes mellitus at low plasma vitamin $\mathrm{E}$ concentrations: a four year follow up study in men. BMJ 1995;311:1124-7.

5 Tuomainen T-P, Punnonen K, Nyyssönen K, Salonen JT. Association between body iron stores and the risk of acute myocardial infarction in men. Circulation 1998;97:1461-6.

(Accepted 28 July 1998)
Research Institute of Public Health, and Department of Public Health and General Practice,

University of

Kuopio, PO Box

1627, 70211

Kuopio, Finland

Jukka T Salonen,

professor of

epidemiology

Tomi-Pekka

Tuomainen,

research fellow

Kristiina

Nyyssönen,

clinical chemist

Hanna-Maaria

Lakka,

research fellow

Department of

Clinical Chemistry,

Kuopio University

Hospital, PO Box

1777, 70211

Kuopio

Kari Punnonen,

clinical chemist

Correspondence to:

Prof Salonen

jukka.salonen@uku.fi

BMJ 1998;317:727 